\title{
Memória e poesia: imagens da palavra de Guimarães Rosa no cinema
}

\author{
Elzira Divina Perpétua e Anita Leandro*
}

\section{Resumo}

Nosso propósito é refletir sobre como é possível, ao cinema e à literatura, chegar a formas de diálogo em que se diluem as fronteiras no processo criativo das narrativas literária e fílmica. Para explorarmos alguns métodos de adaptação pelo cinema que se desenvolvem como processos de criação paralela à obra escrita, enfatizamos o modo como o primeiro encantamento de Riobaldo e Diadorim, ainda meninos, salta das páginas de Grande Sertão: Veredas para ser redimensionado como outra forma de poesia audiovisual em Rio de-Janeiro, Minas, curta-metragem de Marily da Cunha Bezerra, cuja sensibilidade atualiza o texto escrito, potencializando as dimensões sonora e visual presentes na palavra roseana.

Palavras-chave: adaptação; memória; Guimarães Rosa

\begin{abstract}
Our purpose is to reflect about the possibility that film and literature have forms of dialogue in which their boundaries are blurred in the creative process of literary and filmic narratives. In order to explore some methods of adaptation for cinema that develop as a parallel creative processes to the written work, we emphasize how the first spell of Riobaldo and Diadorim, when children, jumps from the pages of Grande Sertão: Veredas [The Devil to Pay in the Backlands] to be resized as another form of visual poetry in Rio de-Janeiro, Minas, short film by Marily da Cunha Bezerra, whose sensitivity updates the written text enhancing the sound and visual dimensions present in the novel by Guimarães Rosa.
\end{abstract}

Key-words: adptation; memory; Guimarães Rosa

As variadas adaptações da obra de Guimarães Rosa oferecem um amplo leque para as reflexões sobre o texto literário projetado em imagens. Nossa proposta se assenta no fato de que a incomensurável rede de significações do texto de Rosa determina a dificuldade de sua transposição para outro tipo de mídia, sendo esta barreira, porém, o principal condutor das soluções encontradas pelos cineastas que se aventuraram a transformar em imagens a escrita roseana. Esse processo criativo, embora arriscado, não esmoreceu dezenas de cineastas que levaram às telas as histórias

"Elzira Divina Perpétua (UFOP - Universidade Federal de Ouro Preto); ICHS; Departamento de Letras; campus Mariana; MG; Brasil, elzira@ichs.ufop.br; Anita Leandro (UFRJ - Universidade Federal do Rio de Janeiro); ECO; Rio de Janeiro; RJ; Brasil, anita.sleandro@gmail.com.

Revista Leitura v.2 no 54 - Júlio/Dez 2014 - Número temático: Leituras interartes. Memória e poesia: imagens da palaura de Guimarães Rosa no cinema. Elzira Divina Perpétua e Anita Leandro. p. 127 - 137. 
imortalizadas pelo escritor mineiro. Entre mais de duas dezenas de filmes adaptados de seus livros, nota-se que a rede de significações do texto de Rosaparece ser o fator determinante tanto para as soluções criativas dos que se arriscaram a transformar em imagens a palavra roseana quanto para aqueles cuja dificuldade de transposição do texto para a tela resultou em produções pífias ou quase protocolares. No levantamento da filmografia sobre a obra de Rosa feito em 2014, consta um total de 26 filmes, entre documentário e ficção, para exibição em cinema e TV, distribuídos comercialmente no Brasil desde 1964, sendo treze curtas e treze longas-metragens, abaixo elencados:

Curtas-metragens e respectivos diretores: A João Guimarães Rosa (1968), de Roberto Santos; A criação literária de João Guimarães Rosa (1969), de Paulo Thiago; Do sertão ao Beco da Lapa (1972), de Maurice Capovilla / Globo Shell Especial, TV Globo; Veredas de Minas (1975), de David Neves e Fernando Sabino; Eu carrego o sertão dentro de mim (1980), de Geraldo Sarno; João Rosa (1980), de Helvécio Ratton; Famigerado (1991), de Aluízio Salles Jr.; Rio de-Janeiro, Minas (1993), de Marily da Cunha Bezerra; Urucuia: um nosso vão de riquezas (1998), de Angélica del Nery; Cordisburgo roseana: a cidade recriada (2001), de Vítor da Costa Borysow; Desenredo (2001), de Raquel de Almeida Prado; Diário do sertão (2003), de Laura Erber; Livro para Manuelzão (2003), de Angélica del Nery.

Longas-metragens e diretores: Deus e o Diabo na Terra do Sol (1964), de Glauber Rocha; O grande sertão (1965), de Renato Santos Pereira e Geraldo Santos Pereira; A hora e a vez de Augusto Matraga (1965), de Roberto Santos; Sagarana, o duelo (1973), de Paulo Thiago; Cabaret mineiro (1980), de Carlos Alberto Prates Correia; Noites do sertão (1984), de Carlos Alberto Prates Correia; Cinema falado (1986), de Caetano Veloso; A terceira margem do rio (1994), de Nelson Pereira dos Santos; Outras estórias (1999), de Pedro Bial; Aboio (2005), de Marília Rocha; Mutum (2007), de Sandra Kogut; A hora e a vez de Augusto Matraga (2011), de Vinícius Coimbra; Grande sertão: veredas (1985) - minissérie TV Globo, de Walter Avancini.

Embora estejam inseridos na filmografia da obra de Rosa, é necessário explicitar que alguns dos filmes elencados não se configuram como adaptação direta, mas como variadas formas de diálogo com o texto roseano. É o caso do curta Urucuia: um nosso vão de riquezas, que enfoca poeticamente a vida sertaneja numa das regiões nortemineiras imortalizadas pelo escritor. Dos longas, destacamos diferentes relações com o texto: Cabaret Mineiro, adaptação livre do universo roseano, contém referência mais

\footnotetext{
Revista Leitura v.2 no 54 - Júlio/Dez 2014 - Número temático: Leituras interartes. Memória e poesia: imagens da palaura de Guimarães Rosa no cinema. Elzira Divina Perpétua e Anita Leandro. p. 127 - 137.
} 
direta ao conto "Soroco, sua mãe, sua filha"; Cinema Falado comporta uma citação literal de grande trecho de Grande Sertão: Veredas em uma performance de 15 minutos do ator Hamilton Vaz, após comentário sobre a obra adaptada para a televisão por Walter Avancini; Aboio, que registra a cultura e a poesia dos aboiadores de Minas e de outros estados, foi realizado a partir das referências encontradas na obra de Rosa, conforme explica em entrevista a diretora do filme Marília Rocha (MERTEN, 2005). Também não é transposição da escrita roseana o consagrado Deus e o Diabo na Terra do Sol, sendo notória a leitura de Grande Sertão: Veredas como mote da obra de Glauber, em especial nesse filme, de acordo com GALVÃO (2009) e DEBBS (2010, p.116).

Fora do circuito comercial, constam seis filmes de média-metragem realizados por Anita Leandro, professora de Cinema da Universidade Federal do Rio de Janeiro, em parceria com Dôra Guimarães e Elisa Almeida: Lélio e Lina (2009); Chefes e outros (2009); Animaizinhos (2010); O recado do morro (2011); Soroco (2011); O pacto de Riobaldo (2011).Trata-se de filmagens de narrações dirigidas por Dôra Guimarães e Elisa Almeida, feitas por crianças e adolescentes de grupos que elas coordenam, respectivamente, do Grupo Miguilim de Contadores de Estórias de Cordisburgo, cidademineira onde nasceu o escritor, e do Grupo de Contadores de Estórias de Morro da Garça, cidadevizinha, integrante do universo da vida e obra de Rosa.

Dos curtas-metragens, apenas três são baseados na ficção roseana, sendo dois originários de contos (Famigerado, de Aluízio Salles Jr., e Desenredo, de Raquel de Almeida Prado) e um de trecho de Grande Sertão: Veredas (Rio de-Janeiro, Minas, de Marily da Cunha Bezerra), sobre o qual se assenta o presente estudo.

Embora os dez curtas apontados como documentário possuam ampla variação temática, o sertão é topos recorrente na maior parte deles. Outros dois temas comuns são a biografia do escritor e a vida de seus personagens factuais. Chama ainda atenção o aparecimento de um mesmo texto em mais de uma adaptação fílmica, em longas ou curta-metragens - os contos "Famigerado", “Os Irmãos Dagobé”, "A hora e vez de Augusto Matraga", "Soroco, sua mãe, sua filha" e o romance Grande Sertão: Veredas que, além de duas adaptações integrais, uma para cinema e outra para televisão, possui trechos citados em pelo menos mais um longa e nove curtas. Como também é notável o fato de que, à exceção dos dois livros em prosa lançados postumamente (Outras Estórias e Ave Palavra), as demais obras narrativas de Rosa são contempladas nas

\footnotetext{
Revista Leitura v.2 no 54 - Júlio/Dez 2014 - Número temático: Leituras interartes. Memória e poesia: imagens da palaura de Guimarães Rosa no cinema. Elzira Divina Perpétua e Anita Leandro. p. 127 - 137.
} 
realizações cinematográficas - Sagarana, Corpo de Baile (composto pela trilogia Manuelzão e Miguilim, No Urubuquaquá, no Pinhém e Noites do Sertão), Primeiras Estórias, Tutaméiae Grande Sertão: Veredas.

O grande número de filmes baseados na escrita de Rosa nos levou a formular a hipótese de que haveria uma espécie de imagem da memória cristalizada na palavra roseana, que dispõe seus textos ao cinema. No âmbito dos Estudos Comparados, os críticos reconhecem uma necessária infidelidade ao texto para se chegar a uma transposição esteticamente viável, obtida através de criação paralela. Resistindo aos termos da mera comparação e do julgamento ingênuo de que o texto roseano seja superior às suas adaptações para o cinema ou televisão, nosso propósito é refletir sobre como cinema e literatura estabelecem formas de diálogo em que se diluem as fronteiras entre o processo criativo das narrativas literária e fílmica.

O recorte privilegiado no presente estudo será a comparação entre os aspectos espaço temporais do texto de Rosa, em suas dimensões física e metafísica, e o modo como o cinema incorpora essas dimensões, potencializando as marcas mnêmicas do romance de Rosa. Para isso tomaremos como campo de análise o curta-metragem Rio de-Janeiro, Minas, realizado por Marily da Cunha Bezerra em 1993. Trata-se de um filme que transpõe, em 8 minutos, trecho dos mais significativos de Grande Sertão: Veredas: o momento em que Riobaldo, ao indagar ao seu interlocutor sobre o sentido do encontro na existência humana, retoma a imagem mais antiga de Diadorim para narrar a primeira vez em que se viram, adolescentes, no porto do pequeno afluente, o Rio deJaneiro, e a travessia de ambos sobre a imensidão das águas do São Francisco.

\section{Poética visual e sonora}

O filme é realizado num cenário despojado, focalizando inicialmente um lugarejo de parcos recursos econômicos, poucas habitações e um número pequeno de figurantes, em contraste com a vegetação exuberante e as dimensões de um grande rio. Na abertura, enquanto a tela é atravessada pelas águas do São Francisco, a voz do narrador, em off, soa grave e compassada, marcada com grande pausas: "São memórias? Sonhos são? É como conto. Vou lhe falar do sertão. Do que não sei. Um grande sertão. Não sei.” Esta breve fala, retomada parcialmente do início da história rememorada por Riobaldo no romance (ROSA, 2006, p.100), introduz o espectador no universo da dúvida, do não

\footnotetext{
Revista Leitura v.2 no 54 - Júlio/Dez 2014 - Número temático: Leituras interartes. Memória e poesia: imagens da palaura de Guimarães Rosa no cinema. Elzira Divina Perpétua e Anita Leandro. p. 127 - 137.
} 
saber, aproximando duas instâncias elaboradas em grande parte pelo inconsciente, confundido-as: a memória e o sonho.

Na sequencia, um jovem descalço, vestes simples, estanca seus passos no chão de terra para dar passagem a um porco que lhe atravessa o caminho, índices da precária condição de vida do lugar. Num plano aberto, o fundo da tela descortina, na estrada, um vulto que caminha na direção da câmera. A voz do narrador retoma o fio narrativo, situando o episódio num tempo marcado pela inexatidão, pelo espaço lacunar próprio da rememoração: "O fato se deu um dia, faz tanto... Eu devia estar com uns 14 anos. Eu tinha acabado de sarar de uma doença e minha mãe tinha feito uma promessa para eu cumprir." A promessa era pedir esmolas em nome do Senhor Bom Jesus da Lapa, guardando a dádiva numa pequena sacola de pano.

À chegada do jovem, cantos de passarinho e o crocitar insistente de um papagaio compõem a cena que se passa num vilarejo de poucas casas, uma casa comercial, duas ou três pessoas além do menino. A figura de outro rapazinho aparece, no fundo do quadro, enquanto o olhar do adolescente pousa sobre três homens que negociam mercadorias no sistema de trocas. O narrador explica que até gostava de "tirar esmolas", porque isso lhe proporcionava ver o movimento da rua: "queria novidade quieta para meus olhos". Porém a novidade que surge deixará para trás a quietude apaziguadora do rapaz, a partir do momento em que a câmera focaliza, em close, o rosto do menino forasteiro que acabara de se instalar, sorridente, dentes brancos, pele clara, olhos verdes, cabelos lisos sob o chapéu elegante, à sombra de uma grande árvore.A câmera guia o espectador, chamando a atenção para a primeira troca de olhar entre os meninos, encontro de olhares tão significativo que produz, no plano seguinte, a reação envergonhada do jovem pedinte, que dobra rapidamente o saco de esmolar, guardando-o no bolso da calça.

À medida que os meninos se aproximam sob a copa da grande árvore, o narrador reproduz a indagação retórica de Riobaldo: "Por que foi que eu tinha que encontrar aquele menino? Aquele menino... Como eu ia poder deslembrar? Ele era muito diferente." Enquanto a câmera focaliza o rosto do forasteiro, enfatizando a fumaça do cigarro que ele traga, o narrador descreve o que a memória não quer deslembrar - o traço físico marcante e o sentimento que o inunda naquele momento: "Os olhos grandes, verdes. Foi nascendo uma vontade de que ele não fosse embora, ficasse só meu companheiro." A cena fixa o momento, ao passo que o texto do romance, ao utilizar o

\footnotetext{
Revista Leitura v.2 no 54 - Júlio/Dez 2014 - Número temático: Leituras interartes. Memória e poesia: imagens da palaura de Guimarães Rosa no cinema. Elzira Divina Perpétua e Anita Leandro. p. 127 - 137.
} 
gerúndio, "foi nascendo", provoca uma extensão do tempo lembrado. Interessa ainda observar que, no filme, o fato de a cena deste encontro se passar sob a copa de uma árvore - símbolo da grandeza e da perenidade -, no contexto da trama, ampara a importância do sentimento ainda impossível de ser compreendido e verbalizado em seu significado real e, por isso, definido pelo narrador "apenas" como desejo de que aquele encontro fosse para sempre.

A seguir, os dois meninos saem à porta da venda e a música de Badi Assad invade a cena. No quadro, um ramo de rosas vermelhas abertas evoca o que vai com eles a partir daí, antecipando, nesse curto plano, o amor de Riobaldo e Diadorim. ${ }^{\dagger}$ A ênfase na imagem das rosas potencializa, assim, um símbolo já mencionado no romance, porém enumerado junto com outros elementos na descrição que o narrador de Grande Sertão faz do porto do Rio de-Janeiro: "Porto, lá como quem diz, porque outro nome não há. Assim sendo, verdade, que se chama, no sertão: é uma beira de barranco, com uma venda, uma casa, um curral e um paiol de depósito. Cereais. Tinha até um pé de roseira. Rosmes!...” (ROSA, 2006, p. 101).

À beira do rio, o forasteiro estende a mão ao nativo para sua entrada na canoa, enquanto o narrador rememora os sentimentos antagônicos que vão guiar a relação de ambos quando adultos: "Amigo desconhecido, a amizade dele ele me dava. E amizade dada não é amor?" Leitor e espectador podem estranhar o fato de o nativo não estar familiarizado com o rio, enquanto o forasteiro se sente muito à vontade no mundo ribeirinho. Situada, porém, na dimensão simbólica do encontro, a travessia das duas águas - a do Rio de-Janeiro e a do São Francisco - redefine o espaço mítico que o romance de Rosa designa para selar o destino dos dois personagens, espaço este reativado na adaptação de Marily Bezerra. Tanto que, na cena final, enquanto a canoa atravessa de volta o grande rio e novamente a música de Badi Assad inunda a cena, o símbolo matemático do infinito -adotado por Rosa em seus manuscritos e tomado como representação da perenidade - aparece na tela,num travelling horizontal, no sentido da correnteza, como que acompanhando a canoa que desliza.

Em poucos minutos, o filme condensa as páginas da obra em que o episódio é narrado, redimensionando a potência da imagem e dos sons previstos no texto. Preserva

\footnotetext{
${ }^{\dagger}$ A partir de um minucioso levantamento de Grande Sertão: Veredas, MARQUEZINI \& BONFIM (2009) conduzem uma interessante análise de outros elementos desse filme como indícios simbólicos do amor e do sofrimento previstos na história futura dos dois protagonistas.
} 
o mínimo de palavras, obtendo da voz do ator-narrador o tom intimista das reflexões de Riobaldo, e favorece a transposição de uma ação expressa. Substitui também o diálogo dos meninos pelo foco na expressão visual e corporal dos protagonistas que aqui sintetizamos como o jogo comparativo entre a simplicidade das vestes de um e a elegância do outro, entre a timidez do primeiro e a desenvoltura do segundo, entre o medo do menino e a coragem do amigo.

No filme, enquanto a voz narrativa expõe reflexões acerca da vida, da amizade, da coragem e do medo, a imagem mostra o desenrolar da ação em câmara subjetiva, do ponto de vista dos meninos. Assim, acompanhamos o balanço das águas, o deslizar da canoa, o bater dos remos, em movimentos que se coadunam aos sons da natureza, da água e dos bichos - cágado, sapos, pássaros. Movimentos e sons que se alternam entre rapidez e lassidão, entre rispidez e delicadeza, música e longos momentos de silêncio, em passo alternado também com o jogo de luz e sombra. Essas oposições sugerem a perplexidade do menino nativo diante de sentimentos até então desconhecidos, que são traduzidos pelo narrador memorialista em sentenças descontínuas como "Eu estava indo a meu esmo", quando funde a visão das águas claras do rio de-janeiro com o olhos de Diadorim; e "Amanheci minha aurora", para expressar a sensação corporal de ter a mão de Diadorim sobre a sua. Tal perplexidade culminará com a aparente divergência de sentido da frase do memorialista no retorno da travessia do São Francisco: "Eu não sentia nada, só uma transformação: eu não tinha medo mais”. Tais sentenças, amalgamadas à paisagem ribeirinha e aos gestos e silêncios dos protagonistas, ganham sentido com as imagens escolhidas por Marily Bezerra e perfazem um todo poético que presentifica o texto de Rosa ao mesmo tempo em que cria uma nova poética, uma poética visual e sonora.

Esta poética recriada pode ser confirmada por certa fidelidade das imagens projetadas às imagens mentais do texto original, imagens cristalizadas a partir das escolhas da locação e do elenco. A ambientação recorre à paisagem do sertão, com seus bichos e rios, à simplicidade da arquitetura de casas e embarcações, à indumentária de personagens e figurantes, à participação de Manuelzão, personagem factual recriado por Rosa em "Uma estória de amor”, à voz em off do ator-narrador, José Mayer. A poética é ainda recriada pela supressão dos diálogos, por uma inovadora reordenação do texto adaptado, pela inserção das reflexões do protagonista em momentos diferentes do que

\footnotetext{
Revista Leitura v.2 no 54 - Júlio/Dez 2014 - Número temático: Leituras interartes. Memória e poesia: imagens da palaura de Guimarães Rosa no cinema. Elzira Divina Perpétua e Anita Leandro. p. 127 - 137.
} 
ocorre no texto de origem e pela adaptação de trechos do episódio do encontro dos meninos fundidos com outras passagens do romance.

Por fim, trata-se também de uma poética que rompe com o naturalismo da adaptação na escolha de duas jovens atrizes para a interpretação dos dois personagens roseanos, dois meninos, como consta na obra escrita. Sabe-se que no primeiro encontro entre Riobaldo e Diadorim, assim como ocorre mais tarde, no bando de jagunços, Diadorim se esconde atrás de uma identidade masculina, sendo que o instigante mistério que o cerca só é revelado a Riobaldo após a morte do companheiro, nas páginas finais do romance. No trecho tomado para adaptação, um Riobaldo mais velho e não nomeado dirige sua narrativa à recordação de si com outro menino, à lembrança indelével do primeiro encontro, ao encantamento inesquecível do olhar de Diadorim, ao mistério de como esse encontro alterou sua vida. A androginia aparente das duas atrizes introduz novos pontos instigantes no diálogo possível, poético e criativo entre literatura e cinema.

Ao se concentrar numa única cena do romance, em que a materialidade do texto original do narrador é preservada, Marily Bezerra cria as condições de possibilidade para que a passagem da literatura ao cinema se faça de maneira solidária, estabelecendo, entre as duas formas de escrita, uma relação de cumplicidade, de complementação. Mais do que uma simples adaptação, esse filme sem diálogos é uma reverberação dos elementos sonoros e visuais do texto adaptado. Grande conhecedora da obra de Rosa, a cineasta penetra, com esse pequeno curta-metragem, na essência da relação espaço temporal em Grande Sertão: Veredas. Instalada numa geografia infinita, traçada em ziguezague e que a todo momento rouba a cena, em descrições da paisagem e da vida no sertão tomadas de empréstimo à poesia, a narrativa de Rosa oferece ao leitor uma experiência do tempo que não passa pelo encadeamento das ações dos personagens, mas pelos intervalos que as permeiam. Essa experiência direta do tempo, que Deleuze nomeou "situação ótica e sonora pura" (DELEUZE, 1985, p. 8-9) e que o cinema só passaria a explorar de forma mais arrojada depois da Segunda Guerra Mundial, com o neorrealismo italiano, Rosa pratica, em seu livro, com os meios da literatura.

A “imagem-tempo" deleuziana, imagem puramente ótica e sonora, liberada dos encadeamentos sensório-motores das narrativas lineares, é, no cinema, marcada pela profundidade de campo, pelo plano sequência e pela duração (DELEUZE, 1985, p. 10). $\mathrm{Na}$ literatura de Rosa ela corresponderia àqueles longos momentos em que o leitor se

\footnotetext{
Revista Leitura v.2 no 54 - Júlio/Dez 2014 - Número temático: Leituras interartes. Memória e poesia: imagens da palaura de Guimarães Rosa no cinema. Elzira Divina Perpétua e Anita Leandro. p. 127 - 137.
} 
confronta à experiência sensível do encontro com uma paisagem e com os seres que nela habitam. Na obra roseana, está em jogo algo muito parecido com o que Deleuze viu no cinema moderno e que remete a uma representação direta do tempo, que não passa mais pelo encadeamento cronológico dos acontecimentos. Trata-se de um novo regime de imagem, que não se limita à terceira dimensão do visível. Ela atinge uma quarta dimensão, propriamente espiritual, que é, segundo o pensador francês, "o não evocável em Welles, o inexplicável em Robbe-Grillet, o irresolúvel em Resnais, o impossível em Marguerite Duras, ou ainda aquilo a que poderíamos chamar o incomensurável em Godard" (Deleuze, p. 237). Ao que poderíamos acrescentar: o audível e o visível no texto de Rosa - dimensões inesperadas num texto literário, mas que a dilatação do tempo narrativo tornam sensíveis.

Ao transformar em voz off a voz do narrador do romance, mantendo em silêncio, ao longo de quase todo o filme, suas jovens atrizes, a escrita de Marily Bezerra se coloca lado a lado com a escrita de Rosa. No filme, a ação, literalmente, flutua numa situação ótica e sonora pura. A canoa atravessa o rio com dois personagens silenciosos, embalados pelo marulhar das águas, por frases esparsas, pronunciadas pela voz sussurrada de um narrador invisível, e por duas únicas frases de Diadorim - "Carece de ter coragem." e “Atravessa!”. Ambas as frases são também um sussurro em que não se distingue se é voz de jovem, mulher ou criança - voz da memória que reverbera na narrativa fílmica e sintetiza a aguerrida disposição do companheiro de Riobaldo nas lutas como na vida, demonstrada nessa aventura sobre a frágil canoa,na travessia do São Francisco.

Um dos mais interessantes artifícios da memória narrativa recriada por Marily Bezerra ocorre na montagem da cena que justapõe a frase de Diadorim à voz do narrador, que repete "Carece de ter coragem", numa retomada imediata do discurso do personagem.Esta fusão de vozes, ao criar a condição para que a memória auditiva ecoe na fala do narrador, potencializa a representação da memória no cinema, já que a voz do personagem, no passado, ativa a voz do presente narrativo. Assim, o filme leva ao extremo a feliz experiência, já concretizada pela voz do narrador invisível, de indicar com poucas palavras a presença da memória. Memória esta que no romance é presentificada não apenas por intermédio da narrativa retrospectiva em primeira pessoa, como também através das lacunas e dos saltos no tempo dos acontecimentos lembrados por Riobaldo. Não é preciso mostrar muito nem dizer muita coisa, sobretudo num curta-

\footnotetext{
Revista Leitura v.2 no 54 - Júlio/Dez 2014 - Número temático: Leituras interartes. Memória e poesia: imagens da palaura de Guimarães Rosa no cinema. Elzira Divina Perpétua e Anita Leandro. p. 127 - 137.
} 
metragem. Bazin diria, em situações como esta, que o cineasta não é mais o concorrente do pintor e do dramaturgo, mas, enfim, o equivalente do romancista. A imagem de cinema, sua estrutura plástica, sua organização no tempo, "posto que ela se apoia em um realismo maior", dispõe de meios para modificar de dentro a realidade. E é por isso que adaptar não é mais trair, "mas respeitar". O cineasta moderno, como Bresson, por exemplo, ao adaptar Bernanos, não se contenta mais em pilhar. "Ele propõe transcrever para a tela, uma obra com a qual ele se identifica e cuja transcendência ele reconhece, $a$ priori" (BAZIN, 1994, p. 82).

Enquanto os créditos do filme se sucedem por sobre a imagem da correnteza do rio, a voz do narrador retoma a fala que abre o filme - "Lhe falo do sertão. Do que não sei. Um grande sertão. Não sei” - acrescentando: "Sonhação? Sonhos são? Sonhos só não." Ao extrapolar o significado geográfico da palavra "sertão", o narrador perfaz um ciclo de reflexões sobre a memória, indicando como esta se mistura aos sonhos, mas também como a rememoração compõe uma nova concepção de real. Assim, o real é trazido à tona pela evocação deste filme sobre o sentido da travessia, fazendo voltar à memória do espectador a antológica frase de Grande Sertão: “O real não está na saída nem na chegada: ele se dispõe para a gente é no meio da travessia" (ROSA, 2006, p.64).

\section{Referências}

BAZIN, André.Pouruncinémaimpur. In:Qu'est-ce que lecinéma. Paris: LesEditionsduCerf, 1985.

BEZERRA, Marily da Cunha. Rio de-Janeiro, Minas.Vídeo, cor, 8 min.,1993. Roteiro: Marily da Cunha Bezerra; direção de fotografia: Kátia Coelho; montagem: SarajhYakhni; narração: José Mayer; trilha sonora: Badi Assad; elenco: Nana de Castro; Cristina Ferrantini; Evandro dos Passos Xavier; Paulo de Souza; participação especial: Manuelzão.

BIAGGI, Enio Luiz de Carvalho. Cinema e vídeo na obra de Guimarães Rosa: o percurso das adaptações dos textos rosianos e análise transemiótica da narrativa Carade-Bronze. Em Tese (Belo Horizonte), v.19, p.162-172, 2013.

DEBBS, Sylvie. Os mitos do sertão: emergência de uma identidade nacional. Trad. Sylvia Nemer. 2.ed. Belo Horizonte: C/Arte, 2010.

DELEUZE, Gilles. L'image-temps. Paris: LesEditions de Minuit, 1985.

GALVÃO, Walnice Nogueira. Riqueza e polinização de uma obra. Cinema: veredas os filmes a partir de João Guimarães Rosa. Rio de Janeiro, 24 jun.-6 jul. 2008. In: www.imagemtempo.com.br/guimaraesrosa/artigos.htm. Acesso: maio 2014.

MARQUEZINI, Fabiana Carelli; BONFIM, Júlio César. Num aliso de vereda, eu vi o rio: imagens do Grande Sertão. Verbo de Minas (Juiz de Fora), v.8, n.15, jan.-jun. 2009. MERTEN, Luiz Carlos. Aboio resgata o canto esquecido dos vaqueiros. O Estado de São Paulo. Caderno Cultura. http://cultura.estadao.com.br/noticias/geral,aboio-resgatao-canto-esquecido-dos-vaqueiros,51424. Acesso: agosto 2015.

\footnotetext{
Revista Leitura v.2 no 54 - Júlio/Dez 2014 - Número temático: Leituras interartes. Memória e poesia: imagens da palaura de Guimarães Rosa no cinema. Elzira Divina Perpétua e Anita Leandro. p. 127 - 137.
} 
ROSA, João Guimarães. Grande sertão: veredas. 10.impr. Rio de Janeiro: Nova Fronteira, 2006. 